\title{
INFLUENCIA DEL ALUMINIO SOBRE EL CRECIMIENTO DE LA RAÍZ EN COLIFLOR (Brassica oleracea L., var. Botrytis, Hib. ‘Nevada F1')
}

\author{
INFLUENCE OF ALUMINUM ON ROOT \\ GROWTH IN CAULIFLOWER \\ (Brassica oleracea L., var. Botrytis, Hib. 'Nevada F1')
}

\author{
Fánor Casierra-Posada ${ }^{1}$ \\ Julián F. Cárdenas-Hernández ${ }^{2}$
}

\begin{abstract}
RESUMEN
Entre 40 y $50 \%$ de la superficie cultivable en el mundo corresponde a suelos ácidos con problemas de toxicidad por aluminio, lo cual es uno de los factores que más limitan la producción vegetal en suelos ácidos. Hortalizas, como el coliflor, se desarrollan en Colombia, con frecuencia en suelos ácidos. En Tunja, Colombia, se realizó un ensayo de invernadero para determinar el efecto de la relación $(\mathrm{Ca}+\mathrm{Mg}+\mathrm{K}) / \mathrm{Al}$ sobre el desarrollo de la raíz. El objetivo principal de este trabajo fue el estudio del crecimiento de las raíces y de la acidez titulable medida en la solución nutritiva donde crecían plántulas de coliflor (Brassica oleracea L., var. Botrytis) expuestas a altas concentraciones de aluminio. Las plántulas, se desarrollaron en vasos plásticos con capacidad para 150 $\mathrm{ml}$ de solución nutritiva. Los tratamientos se basaron en una relación $(\mathrm{Ca}+\mathrm{Mg}+\mathrm{K}) / \mathrm{Al}$ equivalente a 1, 0,7 y 0,5 en la solución nutritiva. A la solución de las plantas

${ }^{1}$ Ingeniero Agrónomo PhD., Docente Asociado, Facultad de Ciencias Agropecuarias, Universidad Pedagógica y Tecnológica de Colombia. Apartado aéreo 661, Tunja - Boyacá / Colombia. Grupo de Investigación Ecofisiología Vegetal. E-mail: fcasierra@tunja.uptc.edu.co

2 Estudiante de Ingeniería Agronómica, Universidad Pedagógica y Tecnológica de Colombia, Tunja - Boyacá. E-mail: julianc0182@yahoo.es
\end{abstract}

control no se adicionó aluminio. Luego de 34 días del transplante, se determinó la longitud total de la raíz, el pH y la acidez titulable de la solución nutritiva. La longitud radical, se redujo considerablemente con el aluminio. El pH y la acidez titulable, de igual manera, dependieron de la concentración del metal. Mientras que la acidez titulable se incrementó con el contenido de aluminio, el $\mathrm{pH}$ de la solución se redujo. Los resultados muestran que las raíces de las plantas de coliflor son muy sensibles a la toxicidad por aluminio.

Palabras clave: Toxicidad, estrés por Al, relación $\mathrm{Ca}+\mathrm{Mg}+\mathrm{K} / \mathrm{Al}$.

\section{SUMMARY}

Approximately $40-50 \%$ of the world's potentially arable soils are acidic and aluminum (Al) toxicity has been recognized as one of the most important limiting factors of plant productivity on acidic soils. Vegetables, as cauliflower (Brassica oleracea L., var. Botrytis) are grown in Colombia frequently on acidic soils. A greenhouse experiment was conducted at Tunja, Colombia to determine the relationship between the $(\mathrm{Ca}+\mathrm{Mg}+\mathrm{K}) / \mathrm{Al}$ ratio and root development. The main goal of this work was to study the root growth and the titrable acidity measured in the nutrient solution, where cauliflower seedlings grow, exposed to high aluminum concentrations. Plantlets were 
grown in $150 \mathrm{~mL}$ plastic containers with nutrient solution. Treatments were $(\mathrm{Ca}+\mathrm{Mg}+\mathrm{K}) / \mathrm{Al}$ ratio equivalent to $1,0.7$, and 0.5 in the nutrient solution. To the growth solution of the control plantlets was $\mathrm{Al}$ was added. After 34 days of transplanting, total root length, $\mathrm{pH}$ and titrable acidity of the nutrient solution were measured. The root length was strongly reduced by $\mathrm{Al}$. $\mathrm{pH}$ and the titrable acidity measured in the nutrient solution depended on Al concentration. While the titrable acidity increased as $\mathrm{Al}$ concentration was higher, $\mathrm{pH}$ of the nutrient solution decreased. Results showed that roots of cauliflower plantlets are sensitive to Al toxicity.

Key words: Toxicity, Al stress, relationship $\mathrm{Ca}+\mathrm{Mg}+\mathrm{K} /$ Al.

\section{INTRODUCCIÓN}

El aluminio es el elemento metálico más abundante en la corteza terrestre y constituye cerca de $8 \%$ de su peso. Este elemento es demasiado reactivo para ser encontrado en forma libre, además, en condiciones ligeramente ácidas o neutras $(\mathrm{pH}>6)$, se encuentra unido a los silicatos y a los óxidos minerales y, por tanto, no representa mayores riesgos de toxicidad para los seres vivos; sin embargo, en condiciones fuertemente ácidas, el aluminio se libera a partir de formas insolubles, con lo cual se incrementa su disponibilidad en el suelo y las posibilidades de causar toxicidad a los seres vivos. La química particular, dependiente del pH que presenta el aluminio, puede ser una de las razones por las cuales, a pesar de su abundancia en los sustratos, este elemento no parece ser utilizado con algún propósito biológico conocido y, generalmente, se le reconoce como un elemento no esencial para los seres vivos (Johnson $\mathcal{E}$ Bennet, 1991; Bulanova et al. 2004).

El aluminio tiene la capacidad de alterar el metabolismo celular dependiente del $\mathrm{Ca}^{2+}$, dado que permite la acumulación de niveles de $\mathrm{Ca}^{2+}$ en el citoplasma por encima de los valores normales o impide que se mantenga el $\mathrm{Ca}^{2+}$ en formas transitorias en el citoplasma y, de esta manera, se alteran algunos procesos metabólicos de vital importancia para el vegetal, como la división y la elongación celular (Rengel, 1992). Matsumoto \& Morimura (1980) y Horst et al. (1983) reportaron la inhibición de la multiplicación celular mediante la interacción del aluminio con la cromatina. Por su parte, Horst $\mathcal{E}$ Klotz (1990) encontraron que el aluminio afecta, en primera medida, la elongación celular en lugar de la mitosis en raíces de Glycine max.

Los mecanismos responsables de la reducción de la multiplicación celular en raíces de plantas que han sido expuestas a aluminio son aún tema de investigación. Se ha propuesto que este efecto puede estar relacionado con ciertas alteraciones que el aluminio causa al ADN o a otro tipo de material genético. Parece ser que la acumulación del aluminio en el interior de las células de los ápices de las raíces empieza a los 30 minutos de exposición al metal (Delhaize et al. 1993; Vázquez et al. 1999) y además, se ha demostrado que este elemento se une al núcleo y al ADN de las células (Matsumoto, 1991).

Una cantidad relativamente grande del carbono asimilado mediante el proceso de fotosíntesis, se exuda a través de las raíces de los vegetales. Este carbono está representado en una fracción significativa de ácidos orgánicos de bajo peso molecular, como el oxálico, tartárico, succínico, málico, cítrico y algunos aminoácidos (Marschner, 1995). La concentración de ácidos orgánicos en la solución de suelo es generalmente baja $\left(1 \times 10^{-3}-4 \times 10^{-4} \mathrm{~mol}^{-\mathrm{L}^{-1}}\right)$; sin embargo, se han encontrado grandes cantidades de ácidos orgánicos en la rizósfera de plantas cultivadas. El área de contacto de las raíces con el suelo es una zona de una gran actividad biológica, donde se desarrollan muchos tipos de microorganismos, los cuales son más activos en ese sitio que en el resto del volumen de suelo, y sintetizan muchos ácidos orgánicos alifáticos y fenoles (Vance et al. 1996). La secreción de ácidos orgánicos en plantas expuestas a $\mathrm{Al}^{3+}$, se considera un mecanismo de vital importancia para desarrollar tolerancia a este metal (Ma, 2000). Los canales transportadores de aniones, un tipo de proteína presente en la membrana, regula la secreción de ácidos mediante la activación de los canales por interacción directa del aluminio ya sea con el canal proteico o con un receptor específico en la membrana (Delhaize $\mathcal{E}$ Ryan, 1995; Ma et al. 2001; Piñeros \& Kochian, 2001).

Los exudados de las raíces comprenden sustancias de alto y bajo peso molecular. Las sustancias más importantes de alto peso molecular son el mucílago, los polisacáridos y las ectoenzimas, mientras que los principales constituyentes de los exudados radicales de bajo peso molecular son los carbohidratos, los ácidos orgánicos, los aminoácidos, los péptidos y los fenoles. Mientras 
la toxicidad por aluminio induce la exudación de ácido cítrico en raíces, la deficiencia de fósforo promueve la secreción de ácido oxálico, pero en ambos casos puede suceder la exudación de ácido málico en Glycine max (Liao et al. 2006). La naturaleza de los ácidos orgánicos presentes en la rizósfera difiere con el tipo de planta expuesta a aluminio; en Phleum pratense normalmente se encuentra ácido oxálico, fórmico acético y láctico, pero no se ha detectado ácido málico ni cítrico, muy comunes de encontrar en la rizósfera de otras plantas (Heim et al. 2001). Los ácidos tartárico y oxálico están representados ampliamente en la rizósfera de los suelos y se pueden originar a partir de los procesos de lisis de las células microbiales o provienen de los exudados de las raíces en cereales, leguminosas y solanáceas (Fox $\mathcal{E}$ Comerford, 1990; Ma, 2000; Casierra-Posada, 2001, 2002; Yang et al. 2006). El ácido cítrico exudado por la planta o producido por bacterias en la rizósfera e identificado en los exudados radicales es uno de los ácidos orgánicos más abundantes en la rizósfera (Huang E Violante, 1986; Violante $\mathcal{E}$ Gianfreda, 1995; Vance et al. 1996). Tanto el citrato como el malato tienen un papel muy importante en la tolerancia al aluminio, por tanto, la activación de genes que decodifican el transporte de estos ácidos es vital en la exudación inducida por aluminio (Hoekenga et al. 2006; Yang et al. 2006).

La interacción entre los compuestos bioquímicos y los minerales del suelo, que tiene lugar en la rizosfera, induce la precipitación de los óxidos de hierro y aluminio (Huang E Violante, 1986; Vance et al. 1996). Todos los ácidos orgánicos de bajo peso molecular tienen la posibilidad de interactuar con los productos hidrolíticos de hierro y de aluminio formando precipitados organominerales. La cantidad de precipitados no cristalinos de hierro y de aluminio extraídos es más abundante en la rizosfera que en otras zonas del suelo fuera de ella; además, la cantidad de hierro y de aluminio extraída tiene una correlación positiva con el contenido de carbono, lo que sugiere una asociación química entre esos compuestos orgánicos e inorgánicos (Sarkar et al. 1979). Los precipitados orgánicos de $\mathrm{Al}^{3+}$ en el suelo tienen la capacidad de fijar grandes cantidades de fosfatos (Bloom, 1981; Haynes \& Swift, 1989). Además, la naturaleza y la cantidad de compuestos orgánicos coprecipitados en óxidos de $\mathrm{Al}^{3+}$, así como el área superficial y la cristalinidad de los minerales, juegan un papel muy importante en la adsorción de fosfatos (Violante $\mathcal{E}$ Huang, 1989). Los coprecipitados alumino-orgánicos (como los complejos formados entre aluminio y ácido oxálico), los cuales se pueden formar en la rizósfera y en los suelos ácidos pueden tener una gran influencia sobre la adsorción de fosfatos en ausencia o en presencia de ácidos orgánicos de bajo peso molecular (De Cristofaro et al. 2000).

El objetivo de este trabajo fue la determinación del efecto de la concentración de aluminio, sobre el crecimiento de las raíces y sobre la acidez titulable en la solución nutritiva de plantas de coliflor (Brassica oleracea) cultivadas en solución aireada, bajo condiciones de invernadero.

\section{MATERIALES Y MÉTODOS}

El ensayo tuvo lugar en el invernadero de la Facultad de Ciencias Agropecuarias de la Universidad Pedagógica y Tecnológica de Colombia en Tunja - Colombia, ubicada a 2690msnm. Como material vegetal, se utilizaron plántulas de coliflor del híbrido 'Nevada F1', distribuido en Colombia por la empresa Impulsemillas. Las semillas germinaron en arena previamente lavada con $\mathrm{HCl} 1 \mathrm{~N}$ y enjuagada con abundante agua destilada. Cuando las plántulas desarrollaron entre dos y tres hojas, se trasladaron a vasos plásticos con capacidad para $150 \mathrm{~mL}$. En cada contenedor se colaron $100 \mathrm{~mL}$ de una solución nutritiva, con la siguiente composición (los valores mencionados se adicionaron en $\left.\mathrm{g} \cdot \mathrm{L}^{-1}\right): \mathrm{N}: 0.4, \mathrm{P}_{2} \mathrm{O}_{5}: 0,03$, $\mathrm{K}_{2} \mathrm{O}:$ 0,05, $\mathrm{CaO}:$ 0,0005, MgO: 0,0013, S: 0,00137, B: 0,0002, Cu: 0,00014, Fe: 0,00012, Mn: 0,0013, Mo: 0,00005 y Zn: 0,0002. De acuerdo con la cantidad de calcio, de magnesio y de potasio contenidos en la solución, se adicionó la cantidad de aluminio, de tal manera que se lograra una relación $(\mathrm{Ca}+\mathrm{Mg}+\mathrm{K}) / \mathrm{Al}$ equivalente a $1 ; 0,75$ y 0,5. Esta relación es uno de los criterios para definir como tóxica, una concentración determinada de aluminio en la solución del suelo (Instituto Colombiano Agropecuario, 1992). Como control, se utilizó la solución nutritiva sin la adición de aluminio. Como fuente de aluminio, se empleó $\mathrm{Al}_{2}\left(\mathrm{SO}_{4}\right)_{3} \cdot 18 \mathrm{H}_{2} \mathrm{O}$ (Riedel-de Haën ${ }^{\circledR}$, Alemania). En todos los tratamientos, incluso el control, el pH de la solución se ajustó a 5,5, mediante la adición de $\mathrm{NaOH}$ o $\mathrm{HCl}$ 0,1 N. Los contenedores, se cubrieron con papel de aluminio con el propósito de limitar el crecimiento de algas en la solución. Diariamente, se aireó la solución durante cinco minutos, con la ayuda de motores para acuario, para evitar condiciones de hipoxia en la solución. 
La acidez en la solución nutritiva, se determinó por titulación con $\mathrm{NaOH}$, hasta $\mathrm{pH} 7,2$, determinado con potenciómetro. La longitud total de las raíces se midió seccionando cada una de las raíces de la planta y colocándolas en forma lineal sobre una placa de vidrio con papel milimetrado por debajo. Para visualizar mejor las raíces sobre la placa de vidrio, éstas se tiñeron con solución de safranina durante diez minutos y luego se enjuagaron con etanol al $70 \%$. El peso seco de las raíces, se determinó con la ayuda de una estufa calibrada a $70^{\circ} \mathrm{C}$ durante 24 horas, hasta peso constante.

Se empleó un diseño estadístico completamente al azar con diez replicaciones por tratamiento. Los resultados obtenidos, se analizaron mediante una tabla ANOVA para determinar la significancia. La diferencia entre promedios, se calculó con la prueba Tukey $(P<0,05)$. Los análisis estadísticos, se realizaron con la versión 11.5 de SPSS (Statistical Package for the Social Sciences - SPSS, Inc., Chicago, Illinois).

\section{RESULTADOS Y DISCUSIÓN}

Las plantas que se expusieron a la solución nutritiva con aluminio no mostraron una sintomatología clara en las hojas como consecuencia de la toxicidad por el elemento; sin embargo, en las raíces, los síntomas del efecto negativo del Al fueron bastante claros. Es así como mientras las plantas control presentaban raíces filamentosas, largas y delgadas, en las plantas expuestas al metal, las raíces se hacían más gruesas y cortas en la medida que la relación $(\mathrm{Ca}+\mathrm{Mg}+\mathrm{K}) / \mathrm{Al}$ tenía un valor más reducido (Figura 1).
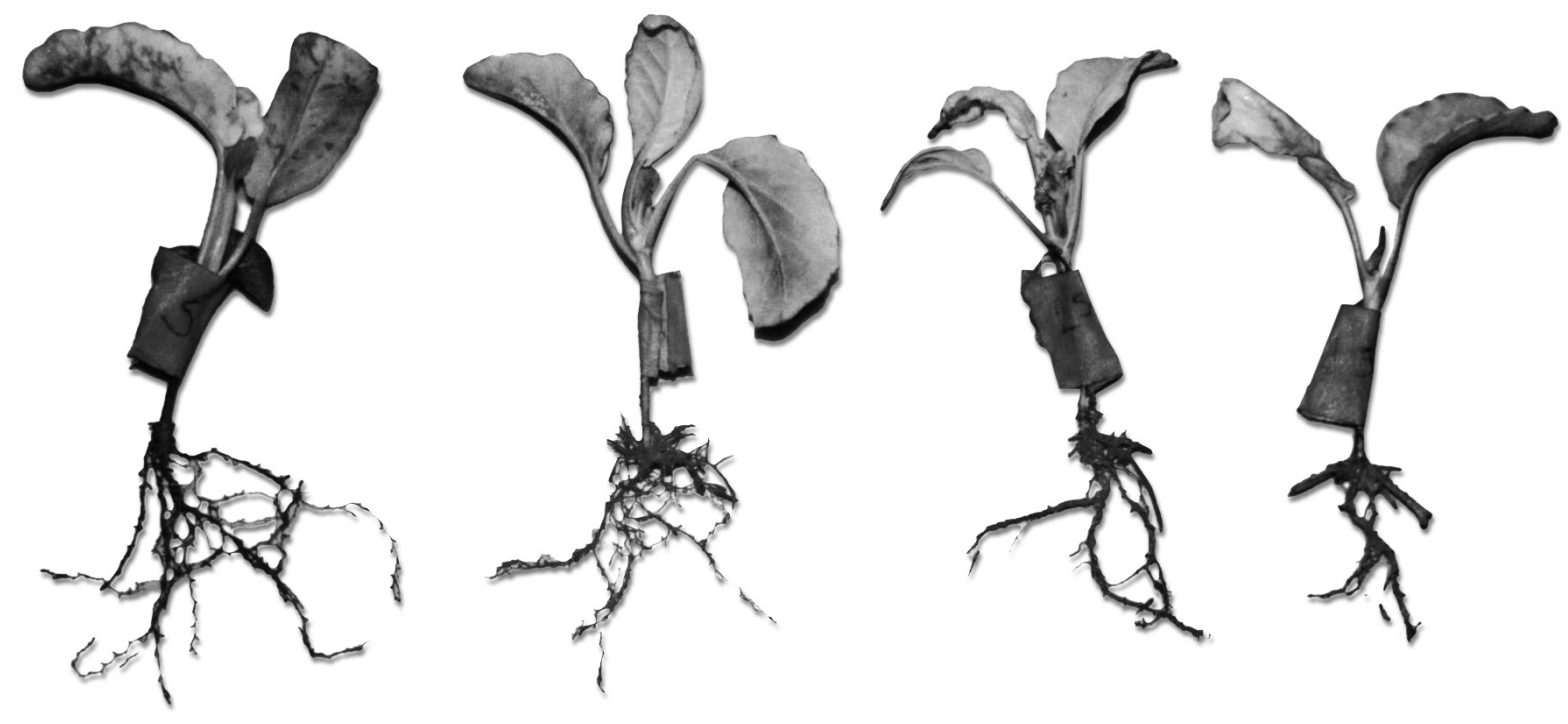

Figura 1. Apariencia externa de las raíces de plantas de coliflor (B. oleracea var. Botrytis) expuestas a diferentes concentraciones de aluminio en la solución nutritiva.

Se encontró que la longitud total de las raíces se redujo en proporciones de 25,7, 29,7 y 53,5\% para los tratamientos con relación bases / Al equivalentes a 1, 0,75 y 0,5 , respectivamente, en relación con las plantas control (Figura 2). En este caso, se encontraron diferencias altamente significativas $(P<0,01)$ entre los tratamientos.
La variable peso seco de las raíces no mostró diferencias significativas, a pesar de lo cual, se notó un incremento entre 25 y $28 \%$ del peso seco encontrado en las raíces de las plantas expuestas a $\mathrm{Al}$, en comparación con las plantas control. 


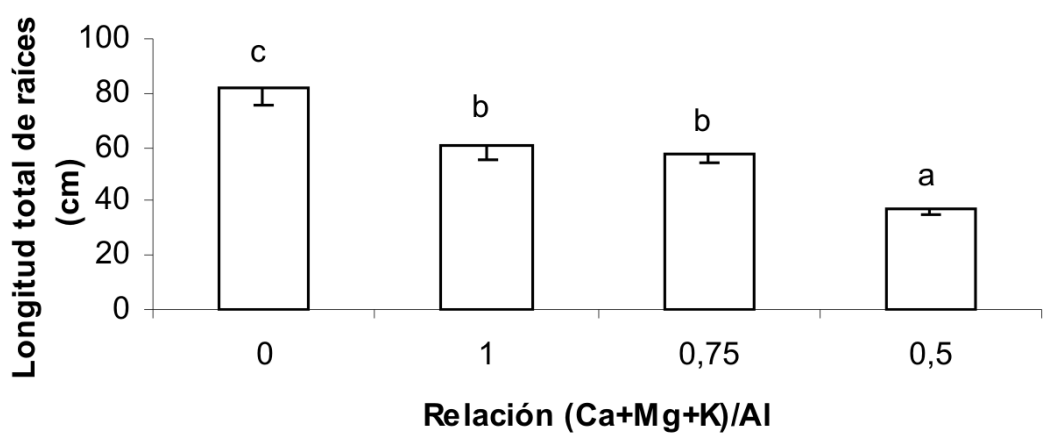

Figura 2. Longitud total de las raíces en plantas de coliflor (B. oleracea var. Botrytis) expuestas a diferentes concentraciones de aluminio.

El efecto de las altas concentraciones de aluminio sobre el crecimiento y el desarrollo radicales debería estar asociado a alteraciones en los mecanismos que determinan la división celular, por tanto, si se tiene en cuenta que los ciclos celulares en los meristemos de las raíces duran aproximadamente entre 18 y 24 horas (Gunning $\&$ Steer, 1996) es poco probable que la reducción de la división celular sea la responsable de la inhibición tan rápida del crecimiento radical, efecto que se expresa a partir de la primera hora de exposición de las raíces a aluminio. Sin embargo, una inhibición sustancial en el crecimiento de las raíces, que se extiende a lo largo de horas, e incluso días, tendría que estar asociada con la reducción de la multiplicación celular (Lazof E Holland, 1999).

Es muy posible que una de las causas de la reducción en la mitosis de meristemos radicales sea una consecuencia de alteraciones inducidas por el aluminio en las moléculas del material genético (Matsumoto, 1991) y, en general, en el núcleo de las células meristemáticas de raíces, pues se ha encontrado que en genotipos sensibles a aluminio, éste se acumula en mayor cuantía y con más rapidez que en materiales tolerantes (Silva et al. 2000). Por tanto, los desórdenes causados tanto en el núcleo de las células como en el material genético tendrían como consecuencia alteraciones en la mitosis, pues es indiscutible el papel protagónico que el ADN y el núcleo tienen en la mitosis.

En relación con la apariencia externa anormal exhibida por las raíces de coliflor que se expusieron a aluminio, se ha encontrado que algunos compuestos que inhiben el funcionamiento normal del citoesqueleto, inhiben también el crecimiento y además dan una apariencia anormal al ápice radical, similar a la inducida en las raíces por la fitotoxicidad por aluminio. En general, muchos factores que contribuyen a la alteración del crecimiento de raíces ocasionan una reorientación en los microtúbulos del citoesqueleto. Por lo tanto, la inhibición del crecimiento y el incremento anormal del diámetro radical que se presenta en las raíces expuestas a aluminio, hacen pensar en el citoesqueleto como un objetivo celular en casos de fitotoxicidad por aluminio (Baskin et al. 1994; Baluška et al. 1996; Baskin \& Wilson, 1997; CasierraPosada, 2002). Es así que la presencia de raíces cortas y gruesas en las plantas estudiadas, como consecuencia del aluminio, sería un síntoma de fitotoxicidad por el metal, máxime, cuando las especies de Brásicas manifiestan una alta sensibilidad a la acidez y a la presencia de aluminio en el sustrato (Clune $\&$ Copeland, 1999; Anoop et al. 2003).

Otro efecto negativo de la modificación en la apariencia externa de las raíces de las plantas expuestas a aluminio es que al hacerse éstas más gruesas se reduce considerablemente el área de contacto de la epidermis con la solución del suelo, limitando así la toma de agua y de nutrientes, con lo cual, la expresión del potencial productivo de las plantas se vería seriamente comprometido.

Los valores de $\mathrm{pH}$ medidos en la solución, antes de la titulación, se modificaron como consecuencia de la concentración de $\mathrm{Al}$ en la solución, de manera que el valor de esta variable se redujo en cantidades de 6,42\%, 25,7\% y 27,34\% en comparación con el valor encontrado en la solución de las plantas control, para los tratamientos con 


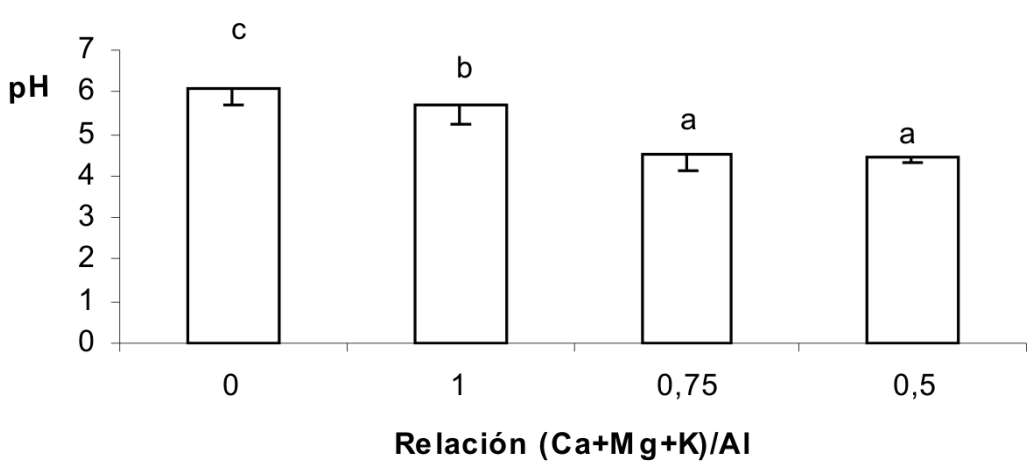

Figura 3. Valor del pH previo a la titulación en la solución nutritiva de plantas de coliflor (B. oleracea var. Botrytis) expuestas a diferentes concentraciones de aluminio en la solución nutritiva.

una relación bases/Al de 1, 0,75 y 0,5 (Figura 3). Se encontraron diferencias altamente significativas $(P<0,01)$ entre los tratamientos.

La acidez titulable expresada en porcentaje de ácido málico presente en la solución nutritiva donde crecieron las plantas, se incrementó en proporción inversa al valor de la relación bases/Al (Figura 4). Esta variable mostró diferencias altamente significativas $(P<0,01)$ entre las diferentes concentraciones de $\mathrm{Al}$ en la solución.

Los resultados muestran claramente que luego de ajustar el $\mathrm{pH}$ a un valor de 5,5, se encontró una reducción en el valor del $\mathrm{pH}$, inversamente proporcional a la cantidad de $\mathrm{Al}_{2}\left(\mathrm{SO}_{4}\right)_{3} \cdot 18 \mathrm{H}_{2} \mathrm{O}$, adicionado a la solución nutritiva, lo cual se pudo deber a la liberación de protones luego de reaccionar el sulfato de aluminio con los compuestos de la solución nutritiva y el agua. El aluminio en condiciones ácidas aparece principalmente como $\mathrm{Al}\left(\mathrm{OH}_{2}\right)_{6}{ }^{3+}$ (denominado comúnmente $\mathrm{Al}^{3+}$ ) (Scheffer $\mathcal{E}$ Schachtschabel, 1992; Marschner, 1995); sin embargo, sería difícil entender la naturaleza de la reacción del sulfato de aluminio con los componentes de la solución nutritiva. En cualquier caso, la reducción del $\mathrm{pH}$ de la solución permitió la liberación de formas tóxicas de aluminio que causaron alteraciones en el desarrollo de raíces. Las reacciones del aluminio con los componentes del sustrato son muy complejas y se han desarrollado algunos modelos para comprenderlos, como el modelo gibsita y el modelo de complejos con humus (Simonsson, 2000), no obstante, parece ser que la relación de intercambio $\mathrm{H}^{+} / \mathrm{Al}^{3+}$, es decir, el número de protones consumidos por la fase sólida en el proceso de liberación de $\mathrm{Al}^{3+}$ es determinante, cuando se trata de un sustrato sólido; sin

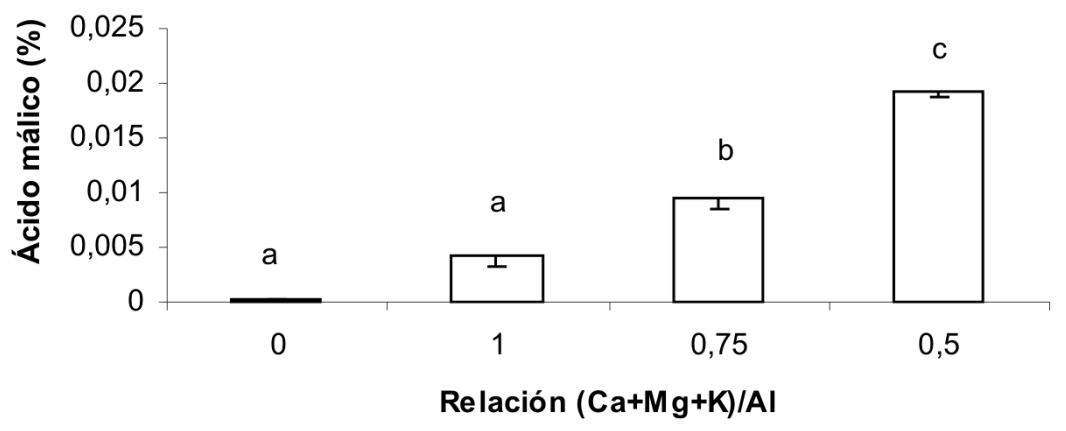

Figura 4. Acidez titulable expresada como porcentaje de ácido málico, determinada en la solución nutritiva de plantas de coliflor (B. oleracea var. Botrytis) expuestas a diferentes concentraciones de aluminio. 
embargo, dado que en el presente ensayo, se utilizó una solución aireada es muy difícil determinar el origen de los protones que motivaron el descenso del $\mathrm{pH}$.

Como consecuencia de la reducción del pH en la solución, el aluminio se hace activo y se convierte en un elemento altamente tóxico para las células vegetales, a lo cual, las plantas responden liberando ácidos orgánicos que contribuyen a reducir los efectos tóxicos del aluminio sobre las células, como sucede en Brassica napus con la exudación de ácido cítrico en respuesta al contenido de aluminio en el sustrato (Anoop et al. 2003). Se ha encontrado que la exudación de ácidos orgánicos en plantas, como reacción a la presencia de aluminio, se considera un mecanismo determinante para desarrollar tolerancia a este metal tóxico (Ma, 2000). En este proceso intervienen canales transportadores de aniones, un tipo de proteína presente en la membrana que regulan la secreción de ácidos mediante la activación de los canales por interacción directa del aluminio ya sea con el canal proteico o con un receptor específico en la membrana (Delhaize E Ryan, 1995; Ma et al. 2001; Piñeros \& Kochian, 2001).

La acidez titulable de la solución en la que crecieron las plantas estuvo en relación directamente proporcional con la cantidad de $\mathrm{Al}_{2}\left(\mathrm{SO}_{4}\right)_{3} \cdot 18 \mathrm{H}_{2} \mathrm{O}$, adicionado a la solución. Lo cual permite la posibilidad de que las plantas reaccionaran exudando una mayor cantidad de ácidos orgánicos en respuesta al contenido de aluminio en la solución, a medida que el valor de $\mathrm{pH}$ se hacía más bajo.

Como consecuencia de la reducción del $\mathrm{pH}$ en las soluciones que contenían aluminio, el crecimiento y el desarrollo de las raíces, se vieron seriamente afectados, mostrando una alta sensibilidad de las plántulas de coliflor a la presencia de aluminio en el sustrato.

\section{AGRADECIMIENTOS}

Este estudio se desarrolló con el apoyo de la Dirección de Investigaciones (DIN) de la Universidad Pedagógica y Tecnológica de Colombia, en el marco del plan de trabajo del grupo de investigación Ecofisiología Vegetal, adscrito al programa de Ingeniería Agronómica de la Facultad de Ciencias Agropecuarias. Además, los autores agradecen la colaboración del ingeniero Hugo Ferney Sáenz, representante de Inpulsemillas, por el suministro del material vegetal para la realización del ensayo, así como al equipo de trabajo del laboratorio Bioplasma, de la UPTC por su colaboración en la realización de las mediciones.

\section{BIBLIOGRAFÍA}

ANOOP, V.M.; BASU, U.; McCAMMON, M.T.; McALISTER-HENN, L.; TAYLOR, G.J. 2003. Modulation of citrate metabolism alters aluminum tolerance in yeast and transgenic canola overexpressing a mitochondrial citrate synthase. Plant Physiol. 132:2205-2217.

BALUŠKA, F.; BARLOW, P.W.; VOLKMANN, D. 1996. Complete desintegration of the microtubular cytoskeleton precedes auxin-mediated reconstruction in postmitotic maize root cells. Plant Cell Physiol. 37:1013-1021.

BASKIN, T.I.; WILSON, J.E. 1997. Inhibitors of protein kinases and phosphatases alter root morphology and disorganize cortical microtubules. Plant Physiol. 113:493-502.

BASKIN, T.I.; WILSON, J.E.; CORK, A.; WILLIAMSON, R.E. 1994. Morphology and microtubule organization in Arabidopsis roots exposed to oryzalin or taxol. Plant Cell Physiol. 35:935-942.

BULANOVA, N.V.; SYNZYNYS, B.I.; KOZ'MIN, G.V.. 2004. Aluminum induces chromosome aberrations in cells of wheat root meristem. Russ. J. Genet. 37(12):1455-1458.

BLOOM, P.R. 1981. Phosphorus adsorption by an aluminum-peat complex. Soil Sci. Soc. Am. J. 45:267-272.

CASIERRA-POSADA, F. 2001. Fundamentos fisiológicos, bioquímicos y anatómicos del estrés por aluminio en vegetales. Revista COMALFI. 28(2):8-19.

CASIERRA-POSADA, F. 2002. Alteraciones inducidas por aluminio en el citoesqueleto de las plantas. Revista COMALFI. 29(2):23-30. 
CLUNE, T.S.; COPELAND, L. 1999. Effects of Al on canola roots. Plant Soil. 216:27-33.

De CRISTOFARO, A.; HE, J.Z.; ZHOU, D.H.; VIOLANTE, A. 2000. Adsorption of phosphate and tartarate on hydroxi-aluminum-oxalate precipitates. Soil. Sci. Soc. Am. J. 64:1347-1355.

DELHAIZE, E.; CRAIG, S.; BEATON, R.J.; BENNET, R.J.; JAGADISH, V.C.; RANDALL, P.J. 1993. Aluminium tolerance in wheat (Triticum aestivum L.) I. Uptake and distribution of aluminium in root apices. Plant Physiol. 103:685-693.

DELHAIZE, E.; RYAN, P.R. 1995. Aluminum toxicity and tolerance in plants. Plant Physiol. 107:315-321.

FOX, T.R.; COMERFORD, N.B. 1990. Low-molecularweight organic acids in selected forest soils of southestern USA. Soil Sci. Soc. Am. J. 43:647678.

GUNNING, B.E.S.; STEER, M.W. 1996. Plant cell biology: Structure and function. Jones and Bartlett ediciones, Sudbury, MA. 130p.

HAYNES, R.J.; SWIFT, R.S. 1989. The effects pf $\mathrm{pH}$ and drying on adsorption of phosphate by aluminum-organic matter associations. J. Soil Sci. 40:773-781.

HEIM, A.; BRUNNER, I.; FREY, B.; LUSTER, J. 2001. Root exudation, organic acids and element distribution in roots of Norway spruce seedlings treated with aluminium in hydroponics. J. Plant. Nutr. Soil Sci. 164:519-526.

HOEKENGA, O.A.; MARON, L.G.; PIÑEROS, M.A.; CANCADO, G.M.; SHAFF, J.;, KOBAYASHI, Y.; RYAN, P.R.; DONG, B.; DELHAIZE, E.; SASAKI, T.; MATSUMOTO, H.; YAMAMOTO, Y.; KOYAMA, H.; KOCHIAN, L.V. 2006. AtALMT1, which encodes a malate transporter, is identified as one of several genes critical for aluminum tolerance in Arabidopsis. P. Natl. Acad. Sci. USA. 20, 103(25):9738-9743

HORST, W.J.; KLOTZ, F. 1990. Screening soybean for aluminum tolerance and adaptation to acid soils.
En: El Basam et al. eds. Genetic aspects of plant mineral nutrition. Kluwer Academic Publ. p.355360.

HORST, W.J.; WAGNER, A.; MARSCHNER, H. 1983. Effect of aluminium on root growth, cell division rate and mineral element contents in roots of $\mathrm{Vi}$ gna unguiculata genotypes. Z. Pflanzenphysiol., 109:95-103.

HUANG, P.M.; VIOLANTE, A. 1986. Influence of organic acids on crystalization and surface properties of precipitation products of aluminum. En: Huang, P.M.; Schnitzer, M. eds. Interactions of soil minerals with natural organics and microbes. SSSA Spec. Publ. Madison. p.159-221.

INSTITUTO COLOMBIANO AGROPECUARIO. 1992. Fertilización en diversos cultivos, quinta aproximación. Produmedios. Bogotá. 64p.

JOHNSON, P.A.; BENNET, R.J. 1991. Aluminium tolerance of root cap cells. J. Plant Physiol. 137:760762.

LAZOF, D.B.; HOLLAND, M.J. 1999. Evaluation of the aluminum-induced root growth inhibition in isolation from low pH effects in Glycine max, Pisum sativum and Phaseolus vulgaris. Aust. J. Plant Physiol. 26:147-157.

LIAO, H.; WAN, H.; SHAFF, J.; WANG, X.; YAN, X.; KOCHIAN, L.V. 2006. Phosphorus and aluminum interactions in soybean in relation to aluminum tolerance. Exudation of specific organic acids from different regions of the intact root system. Plant Physiol. 141(2):674-84.

MA, J.F. 2000. Role of organic acids in detoxification of aluminum in higher plants. Plant Cell Physiol. 41(4):383-390.

MA, J.F.; RYAN, P.R.; DELHAIZE, E. 2001. Aluminium tolerance in plants and the complexing role of organic acids. Trends Plant Sci. 16:273-278.

MARSCHNER, H. 1995. Mineral nutrition of higher plants. $2^{\mathrm{a}}$ ed.; Academic Press, Londres. p.606-613. 
MATSUMOTO, H. 1991. Biochemical mechanism of the toxicity of aluminum and the sequestration of aluminum in plant cells. En: Wright, R.J.; Baligar, V.C; Murrmann, R.P. eds. Plant-Soil Interactions at Low pH. Kluwer Academic Publishers, Dordrecht, The Netherlands, p.825-838

MATSUMOTO, H.; MORIMURA, S. 1980. Repressed template activity of chromatin of pea roots treated by aluminium. Plant Cell Physiol. 21:951-959.

PIÑEROS, M.A.; KOCHIAN, L.V. 2001. A patch- clamp study on the physiology of aluminum toxicity and aluminum tolerance in maize. Identification and characterization of $\mathrm{Al}^{3+}$-induced anion channels. Plant Physiol. 125:292-305.

RENGEL, Z. 1992. Disturbance of cell $\mathrm{Ca}^{2+}$ homeostasis as a primary trigger of Al toxicity syndrome. Plant, Cell and Environmental, 15:931-938.

SARKAR, A.N., JENKINS, D.A.; WIN JONES, R.G. 1979. Modifications to mechanical and mineralogical composition of soil within the rhizosphere. En: Harley, J.L.; R., Scott Russel, R.eds. The soil-root interface. Academic Press, San Diego. p.125136.

SCHEFFER, F.; SCHACHTSCHABEL, P. 1992. Lehrbuch der Bodenkunde. Editorial Enke, Stuttgart (Alemania). p.113-125.

SILVA, I.R.; SMYTH, T.J.; MOXLEY, D.F.; CARTER, T.E.; ALLEN, N.S.; RUFTY, T.W. 2000. Aluminum accumulation at nuclei of cells in the root tip: Fluorescence detection using lumogallion and confocal laser scanning microscopy. Plant Physiol. 123:543-552.
SIMONSSON, M. 2000. Interactions of aluminium and fulvic acid in moderately acid solutions: Stoichiometry of the $\mathrm{H}^{+} / \mathrm{Al}^{3+}$ exchange. Eur. J. Soil Sci. 51:655-666.

VANCE, G.F.; STEVENSON, F.J.; SIDRA, F.J. 1996. Environmental chemistry of aluminum-organic complexes. En: Sposito, G., ed. The environmental chemistry of aluminum. CRC Press, Lewis Publ. Boca Raton, Florida. p.169-220.

VASQUEZ, M.D.; POSCHENRIEDER, C.; CORRALES, I.; BARCELLO, J. 1999. Change in apoplastic aluminum during the initial growth response to aluminum by roots of a tolerant maize variety. Plant Physiol. 119:435-444.

VIOLANTE, A.; GIANFREDA, L. 1995. Adsorption of phosphate on variable charge minerals: Competitive effects and ligands. En: Huang, P.M. et al. eds. Environmental impacts of soil component interactions, Vol. II, Metals, other inorganics, and microbial activities. CRC Press, Lewis Publishers, Boca Raton, Florida. p.29-37

VIOLANTE, A.; HUANG, P.M. 1989. Influence of oxidation treatments on surface and reactivities of short range ordered products of aluminum. Soil Sci. Soc. Am. J. 53:1402-1407.

YANG, J.L., ZHANG, L.; LI, Y.Y.; YOU, J.F.; WU, P.; ZHENG, S.J. 2006. Citrate transporters play a critical role in aluminium-stimulated citrate efflux in rice bean (Vigna umbellata) roots. Ann. Bot. (Inglaterra) 97(4):579-584.

Recibido: Febrero 8 de 2007

Aceptado: Mayo 17 de 2007 